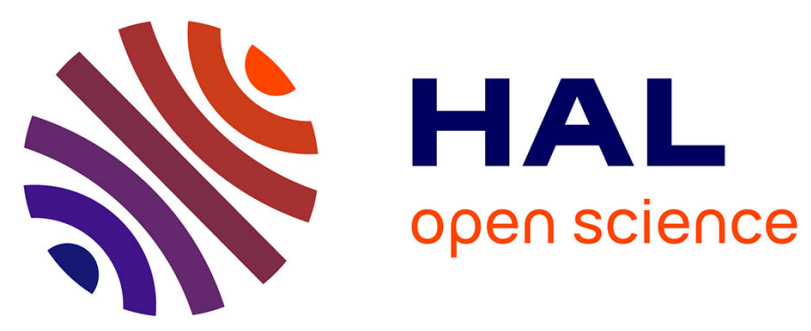

\title{
Battery longevity of neurostimulators in Parkinson disease: A historic cohort study
}

A.L. Sette, E. Seigneuret, F. Reymond, S. Chabardes, A. Castrioto, B. Boussat, E. Moro, P. François, V. Fraix

\section{- To cite this version:}

A.L. Sette, E. Seigneuret, F. Reymond, S. Chabardes, A. Castrioto, et al.. Battery longevity of neurostimulators in Parkinson disease: A historic cohort study. Brain Stimulation, 2019, 12, pp.851 857. 10.1016/j.brs.2019.02.006 . hal-03484381

\section{HAL Id: hal-03484381 \\ https://hal.science/hal-03484381}

Submitted on 20 Dec 2021

HAL is a multi-disciplinary open access archive for the deposit and dissemination of scientific research documents, whether they are published or not. The documents may come from teaching and research institutions in France or abroad, or from public or private research centers.
L'archive ouverte pluridisciplinaire HAL, est destinée au dépôt et à la diffusion de documents scientifiques de niveau recherche, publiés ou non, émanant des établissements d'enseignement et de recherche français ou étrangers, des laboratoires publics ou privés.

\section{다)(1) $(5$}

Distributed under a Creative Commons Attribution - NonCommerciall 4.0 International 
Version of Record: https://www.sciencedirect.com/science/article/pii/S1935861X19300592

Manuscript_7025b8dc8e3e2010d646b84e43aceee2

\section{Battery longevity of neurostimulators in Parkinson disease: a historic cohort study}

Sette A.L., Seigneuret E. MD, Reymond F. MD, Chabardès S. MD, Castrioto A. MD, PhD, Boussat B. MD, PhD, Moro E.MD, PhD, François P. MD, PhD, Fraix V, MD, PhD.

Department of Neurology, Grenoble Alpes University Hospital, Grenoble, France,

Department of Neurosurgery, Grenoble Alpes University Hospital, Grenoble, France,

Department of Pharmaceutical and medical devices, Grenoble Alpes University Hospital, Grenoble, France,

Quality of care unit, Grenoble Alpes University Hospital, Grenoble, France

Grenoble Institute of Neurosciences GIN-INSERM U1216/CEA/UGA, Grenoble, France

Grenoble Alpes University, Grenoble, France

Word count: 3850

Tables: 4

Figures: 2

Corresponding author:

Valerie Fraix

Department of Neurology, Grenoble University Hospital

Grenoble, France.

VFraix@chu-grenoble.fr

Funding:

This research did not receive any specific grant from funding agencies in the public, commercial, or not-for-profit sectors. 
Abbreviations

DBS: deep brain stimulation

STN: subthalamic nucleus

PD: Parkinson disease

RC: rechargeable

TEED: total electrical energy delivered

IPG: implantable pulse generator 
Abstract

Background:

Deep brain stimulation (DBS) of the subthalamic nucleus (STN) is a well-established treatment for motor complications in Parkinson disease (PD). Since 2012, the nonrechargeable dual-channel neurostimulator available in France seems to have shorter battery longevity compared to the same manufacturer's previous model.

Objective:

The aim of this study was to evaluate the battery longevity of older and more recent neurostimulators from the same manufacturer and to explore factors associated with battery life variations.

Materials and Methods

We retrospectively studied our cohort of PD patients who underwent STN DBS between 1987 and 2017. We collected data concerning neurostimulator replacements and parameters. We compared the survival of the first device available, Kinetra ${ }^{\circledR}$ and the current one, Activa-PC ${ }^{\circledR}$ (Medtronic Inc.) and estimated the factors that had an impact on battery longevity through a Cox logistic regression.

Results

Three hundred sixty-four PD patients received a total of 654 DBS STN neurostimulators: 317 Kinetra ${ }^{\circledR}$ and 337 Activa-PC ${ }^{\oplus}$. The survival analysis, using the Kaplan-Meier estimator, showed a difference between the curves of the two devices (log-rank test; $p<0.001$ ). The median survival of an Activa-PC ${ }^{\circledR}$ neurostimulator was 1666 days, while it was 2379 days for a Kinetra ${ }^{\circledR}$.

After adjustment, according to the multivariate analysis, the main factors associated with battery lifetime were: the neurostimulator type; the number of subsequent neurostimulator implantations; the total electrical energy delivered (TEED); and sex.

Conclusion

The Kinetra ${ }^{\circledR}$ neurostimulator lifetime is 2.5 years longer than the Activa-PC ${ }^{\circledR}$. The type of the device, the high TEED and the number of subsequent neurostimulator implantations influence battery 
longevity most. These results have medical-economic implications since the survival of PD patients with DBS increases over years.

Highlights

Different types of neurostimulators are currently available for DBS.

Parkinsonian patients may be operated with a rechargeable or a nonrechargeable device.

The newer dual-channel neurostimulator has a battery lifetime that is 2.5 years shorter than the previous model.

These data have clinical implications and an economic impact.

Keywords: Parkinson disease, deep brain stimulation, neurostimulator, battery longevity. 


\section{Introduction}

Neuromodulation with deep brain stimulation (DBS) has been a well-established treatment for motor complications in Parkinson disease (PD) since the early 1990s [1,2]. The subthalamic nucleus (STN) has been identified as an effective target and has become the most common site for DBS electrode placement [3]. An internal pulse generator (IPG) delivers regular, biphasic, charge-balanced, constant-voltage or -current stimulation. Several parameters can be adjusted during DBS programming such as electrode polarity, amplitude $(\mathrm{V}$ or $\mathrm{mA})$, pulse width $(\mu \mathrm{s})$ and frequency $(\mathrm{Hz})$. With the increased use of DBS therapy, the longevity of nonrechargeable DBS systems raises important clinical and economic issues.

Battery drain is usually associated with clinical worsening and may lead to a loss of control of clinical symptoms. Neurostimulators must sometimes be urgently changed due to the recurrence of neurologic and neuropsychiatric symptoms [4-10]. Moreover, each device's replacement increases the risks of tissue morbidity and infection due to the surgical procedure. It has recently been demonstrated that the rate of infection increases with repeated IPG replacements [11,12]. Finally, periodic replacement also has an economic impact $[15,16]$.

For more than 25 years, Medtronic (Minneapolis, MN, USA) was the only manufacturer providing approved DBS devices. They first developed nonrechargeable neuromodulators (single-channel IPG: Itrel $I^{\circledR}$ and $I^{\circledR}$, Soletra ${ }^{\circledR}$; and dual-channel IPG: Kinetra $\left.{ }^{\circledR}\right)$. Since 2008, the DBS systems provided by Medtronic have been designed as either nonrechargeable (single-channel Activa-SC ${ }^{\circledR}$ and dualchannel Activa-PC ${ }^{\circledR}$ that replaced the Kinetra ${ }^{\circledR}$ ) or rechargeable (RC) (Activa-RC ${ }^{\circledR}$ ). In France, the new generation of the Medtronic nonrechargeable generators (Activa-SC ${ }^{\circledR} \& \mathrm{PC}^{\circledR}$ ) has been available since 2012 and the RC generators (Activa-RC ${ }^{\circledR}$ ) have been available since 2016 for PD patients.

Recently, Helmers et al. (2017) showed that battery life of the first dual-channel neurostimulators was longer than the new ones. This finding seems to confirm a common clinical impression the Activa-PC ${ }^{\circledR}$ devices discharge more quickly [17]. 
The indications for DBS in PD are expanding as patients are operated earlier in the course of the disease, are younger and will live longer with DBS than those operated in the early 1990s. Therefore, they will require several IPG replacements over time. Because of possible economic and clinical implications, there is an increasing need for reliable devices. In this context, the main focus of this study was to compare battery lifetime between the Kinetra ${ }^{\circledR}$ and the Activa-PC ${ }^{\circledR}$ neurostimulators. It also aimed to understand the relationships between battery lifetime, the neurostimulator type, the parameters of stimulation and other variables that could have an impact on battery longevity. The second objective was to estimate the economic impact of repetitive IPG replacements in PD.

\section{Methods}

\section{1) Study design}

The design consisted in a retrospective single-center cohort study to determine the longevity of Kinetra ${ }^{\circledR}$ and Activa-PC ${ }^{\circledast}$ neurostimulators. It was conducted with the data from the Neurology and the Neurosurgery departments of the Grenoble University Hospital (France).

\section{2) DBS devices}

Different models of IPGs manufactured by Medtronic have been implanted since 1987: the Itrel ${ }^{\circledR}$, Itrel $\|^{\circledR}$, Soletra ${ }^{\circledR}$ and Activa $\mathrm{SC}^{\circledR}$ single-channel generators and the Kinetra ${ }^{\circledR}$, Activa $\mathrm{PC}^{\circledR}$ and Activa $\mathrm{RC}^{\circledR}$ dual-channel generators. Kinetra ${ }^{\circledR}$ generators were implanted exclusively from January 1999 until the end of 2011. In 2012, the Soletra ${ }^{\circledR}$ and Kinetra ${ }^{\circledR}$ models of IPGs were replaced by Activa-SC ${ }^{\circledast}$ and Activa-PC ${ }^{\circledR}$ devices. Some patients had neurostimulators provided by other companies that we did not take into account.

Kinetra ${ }^{\circledR}$ and Activa-PC ${ }^{\circledR}$ are dual-channel IPGs allowing bilateral STN stimulation. The most common DBS system consists of a quadripolar lead, a neurostimulator and a subcutaneous extension that connects the lead to the neurostimulator. The IPG is composed of a power source - a hermetically sealed silver vanadium oxide cell - and electronic circuits protected with a hermetic titanium shield $[18,19]$. 
Table 1 summarizes the physical characteristics of the Kinetra ${ }^{\circledR}$ and Activa-PC ${ }^{\circledR}$ devices. Concerning their lifetime, an off-the-shelf Medtronic Kinetra ${ }^{\circledR}$ begins its life with a $3.2 \mathrm{~V}$ voltage, is considered to be in a low-battery status between 2.5 and $2.23 \mathrm{~V}$ and at the end of its life-cycle (EOL) at $2.11 \mathrm{~V}$. The Medtronic Activa-PC ${ }^{\circledR}$ has a starting battery voltage of $3.2 \mathrm{~V}$, is low-battery between 2.6 and $2.3 \mathrm{~V}$ and reaches its EOL at $2.2 \mathrm{~V}$.

In the Grenoble Hospital, batteries are changed when the battery status indicator reaches $2.23 \mathrm{~V}$ or lower values ("battery low" signal) for the Kinetra ${ }^{\circledR}$ and $2.60 \mathrm{~V}$ or lower values (ERI mode) for the Activa-PC ${ }^{\circledR}$.

\section{3) Participants}

We retrospectively identified patients treated with DBS between 01.01.1987 and 01.11.2017. The data set is based on patient files and databases created by the Neurology Department. All patients who have undergone DBS for PD, dystonia, essential tremor, postural tremor or mixed tremor were recorded in this database. They constitute an initial cohort of 845 patients.

We included patients who had the following criteria: idiopathic PD, treatment with bilateral STN DBS, at least one implantation of a dual-channel neurostimulator (Kinetra ${ }^{\circledR}$ or Activa-PC ${ }^{\circledR}$ ) and surgical intervention and patient follow-up conducted at the Grenoble University Hospital. We excluded patients with any other diagnosis than PD, patients who received implants at Grenoble University Hospital but were followed in another DBS center and patients who were not exclusively stimulated in the STN.

\section{4) Data collection}

Data concerning DBS STN replacements and features were found in the patients' files. The exit point from this study was November $30^{\text {th }}, 2017$.

We collected the following patient characteristics: demographic data (sex, age), dates of battery implantation and replacement, and IPG model. PD patients were treated with continuous DBS, i.e., they did not turn off their device during the night. We calculated battery longevity for each IPG. 
We censored data concerning battery removal for other reasons than battery depletion or low voltage (infection, dysfunction). We also censored fresh batteries implanted in patients who died before battery's end of life and batteries that were not depleted at the end of the study period.

To understand the relationships between battery life, battery type and electrical parameters, we collected the last adjustable DBS parameters before battery replacement: amplitude ( $\mathrm{V}$ or $\mathrm{mA})$, stimulated contacts and polarity, frequency $(\mathrm{Hz})$, pulse width $(\mu \mathrm{s})$ and battery status indicator $(\mathrm{V})$, which is an estimation of the remaining battery voltage that varies depending on the battery type. Total electrical energy delivered (TEED) by an electrical device over a period of time is determined with the adjustable DBS settings and the system impedance measured. The following equation is normally used to calculate the TEED $[17,20]$ :

TEED $=\left[\left(\right.\right.$ voltage $^{2 *}$ pulse width*frequency $) /$ impedance $]$

Impedance was not always recorded in the patients' files. As Helmers et al.[17] did, we calculated a modified TEED that did not take into account the impedance, assuming that it changed in the same way for all patients.

For both the Kinetra ${ }^{\circledR}$ and Activa-PC ${ }^{\circledR}$ devices, stimulation parameters are not identical for each hemisphere. For each parameter and for the modified TEED, we calculated a value that is a mean of both leads.

Moreover, both devices' circuits were analyzed by an electronics engineer to test the power source and the electronic circuit.

The data collected are part of the routine care and their analysis did not require further specific consent from the patients.

\section{5) Statistical analysis}

We reported baseline characteristics and stimulation parameters as means and standard deviations (SD) for continuous variables and percentages for categorical variables.

The primary endpoint was to compare the overall survival of both devices (Kinetra ${ }^{\circledR}$ and Activa-PC ${ }^{\circledR}$ ). We used the Kaplan-Meier method to measure overall survival, expressed as the median survival, for 
the Kinetra ${ }^{\circledR}$ and Activa-PC ${ }^{\circledR}$ neurostimulators. The two Kaplan-Meier curves were compared using the log-rank test. Then the association between the DBS neurostimulators' lifetime and the device type was explored using Cox proportional hazard models. The reference category for all analyses was the Kinetra ${ }^{\circledR}$ device. Analyses were adjusted for gender, age at primo-implantation, number of subsequent implantations, modified TEED and number of contacts $\mathrm{ON}$, after a clustering of these continuous variables according to their observed distribution. Two-sided $p$-values were considered statistically significant. All analyses were performed using Stata Version 14.0 (Stata Corporation, College Station, TX, USA).

The secondary endpoint was to estimate the economic impact of repetitive IPG replacements in PD. We collected data concerning the costs of a replacement for the French national healthcare system including the fees associated with surgery, hospitalization and the neurostimulators' prices. These data come from the National Costs' Study of French Hospitals [21].

\section{Results}

\section{1) Population characteristics}

Eight hundred forty-five patients underwent a DBS surgery between January 1987 and November 2017 in the Grenoble Hospital, of whom 663 patients received an implant in the STN for PD. Two hundred ninety-nine patients were excluded because they were lost to follow-up or because the neurostimulators were not an Activa-PC ${ }^{\circledR}$ or Kinetra ${ }^{\circledR}$. Figure 1 represents the study population. Final statistical analysis was performed on 364 patients and 654 DBS devices.

At the primo-implantation, patients were aged $57 \pm 9 ; 118$ patients were women and 246 patients were men. Patients underwent between zero and five replacements, i.e., one to six IPG implantations. One hundred sixty-nine patients had a primo-implantation with no change in IPG, 117 patients had two successive IPG implantations (one replacement), 53 had three successive IPGs (one primo-implantation and two replacements). Twenty-one patients received four successive IPGs (one primo-implantation and three replacements), and three and one patients had five and six successive IPGs, respectively (one primo-implantation and four or five replacements). 


\section{2) Neurostimulator characteristics}

A total of 654 DBS STN neurostimulators were implanted: 317 Kinetra $^{\circledR}$ and 337 Activa-PC ${ }^{\circledR}$. Out of 284 depleted neurostimulators, 237 were Kinetra ${ }^{\circledR}$ neurostimulators and 47 were Activa-PC ${ }^{\circledR}$. Sixty-one neurostimulators' data were censored: 14 neurostimulators were removed for other reasons than battery depletion and 47 fresh neurostimulators were either on patients who had died or were still being used at the end of the study period.

Table 2 recaps data collected and calculations based on neurostimulator parameters. A majority of IPGs were connected to STN leads with at least one contact turned on for each lead, i.e., a minimum of two contacts turned on for one dual-channel IPG. We could not find information for $9 \%$ of the IPGs, so the statistical analysis (see above) was done without them.

Moreover, the volume of the most recent IPG (Activa-PC $\left.{ }^{\circledR}\right)$ is smaller than the previous one, with a ratio of 1.21 in favor of the Kinetra ${ }^{\circledR}$, in terms of size.

\section{3) Mean duration of the depleted neurostimulators}

Three hundred fifty-one neurostimulators were primo-implanted: 220 Kinetra $^{\circledR}$ and 131 Activa-PC $^{\circledR}$. There were more Activa-PC ${ }^{\circledR}$ secondarily implanted than Kinetra ${ }^{\circledR}: 115$ and 63 Activa-PC ${ }^{\circledR}$ were second and third implants, respectively, versus 79 and 16 for Kinetra ${ }^{\circledR}$, respectively. The four neurostimulators implanted as the fifth or sixth implants were Activa-PC ${ }^{\circledR}$. The mean duration of the depleted Kinetra ${ }^{\circledR}$ neurostimulators was $2320 \pm 40$ days ( $6.4 \pm 1.7$ years) and for the Activa-PC ${ }^{\circledR}$ neurostimulators this was $1419 \pm 234$ days ( $3.9 \pm 0.6$ years) ( $p$-value $\left.<0.05\right)$. This amounts to a 901-day difference, i.e., approximately 2.5 years.

The mean duration of a neurostimulator decreased with the successive implants, regardless of the type of neurostimulator (Table 3).

\section{4) Survival analysis}

According to the survival analysis, the median survival of a Kinetra ${ }^{\circledR}$ was 2379 days; the median survival of an Activa-PC was 1666 days. There is a difference of 713 days (log-rank test; $p<0.001$ ), i.e., approximately 2 years (Figure 2 ). 


\section{5) Factors associated with battery longevity}

We used the Cox model to assess associations with battery longevity, such as patient characteristics and stimulation parameters (Table 4). For each variable, we calculated the crude and adjusted hazard ratios (HRa). The analysis was made excluding 17 devices with batteries that missed some stimulation parameters, i.e., it comprised 267 complete observations.

After adjustment, the main factor associated with neurostimulator longevity was the neurostimulator type: the risk of battery depletion is 4.04 times greater for an Activa-PC ${ }^{\circledR}$ neurostimulator than for a Kinetra ${ }^{\circledR}(95 \% \mathrm{Cl}[2.65-6.17])$.

Two other factors increased the risk of battery depletion: later successive implantations (HRa = 1.71; 95\% $\mathrm{Cl}[1.42-2.07])$ and the modified TEED if its value was higher than 70,501 ( $\mathrm{HRa}=1.60 ; 95 \% \mathrm{Cl}$ [1.08-2. 37]). Factors related to patient's sex were also found to be significant.

\section{6) Economic analysis}

We calculated the overall costs of a neurostimulator replacement according to the French national healthcare system. The hospitalization fees including surgery and care were 9121 euros, both for the Kinetra ${ }^{\circledR}$ and the Activa-PC ${ }^{\circledR}$. The cost of the device was 12,292 euros for a Kinetra ${ }^{\circledR}$, and 11,256 euros for an Activa-PC ${ }^{\circledR}$. Consequently, the overall replacement cost for a Kinetra ${ }^{\circledR}$ was 21,413 euros and 20,377 euros for an Activa-PC ${ }^{\circledR}$. If we consider that the median longevity of two successive Kinetra ${ }^{\circledR}$ implantations was approximately equivalent to the median longevity of three successive Activa-PC ${ }^{\circledR}$ devices (13-13.5 years), the implantation of two successive Kinetra ${ }^{\circledR}$ IPGs corresponds to a cost reduction of 18,305 euros per patient over 13 years.

\section{Discussion}

This study shows that the new nonrechargeable DBS neurostimulator Activa-PC ${ }^{\circledR}$ has a shorter battery life than the Kinetra ${ }^{\circledR}$. It confirms clinical observations and previous reports.

In this study, the mean battery life of a Kinetra ${ }^{\circledR}$ was $6.4 \pm 1.7$ years and $3.9 \pm 0.6$ years for the Activa$\mathrm{PC}^{\circledast}$. The mean battery life of a Kinetra ${ }^{\circledR}$ was estimated at $3.0 \pm 0.6$ years by Halpern et al. (2011) and 
$5.44 \pm 0.20$ years by Helmers et al. For the Activa-PC ${ }^{\circledR}$ battery's longevity, Helmers et al. found a mean duration of $4.44 \pm 0.17$ years. These findings are very similar to those reported here, although they were obtained following different analyses and sample populations. The longevity differences among these studies could be explained by differences in the IPG replacement protocol of the neurological and neurosurgical centers concerned.

\section{1) Factors associated with battery longevity}

Several authors have reported that battery longevity could depend on the disease $[9,22]$. Van Riesen et al. demonstrated that IPG longevity in bilateral STN DBS varied according to PD subtype, with the tremor subtype associated with the shortest battery lifetime and higher stimulation parameters. Van Riesen and Helmers's teams also found that battery longevity was influenced by the type of device, the single- or dual-channel feature and the target in the brain $[9,17]$.

In the current study, we found that the main factor influencing battery longevity was the neurostimulator type as well as the number of replacements, the modified TEED and male sex.

\section{Neurostimulator type}

The neurostimulator type mainly impacted battery longevity. This effect is probably mainly due to the technical characteristics of the neurostimulator. The Activa-PC ${ }^{\circledR}$ offers functionalities that are not present in the Kinetra ${ }^{\circledR}$ such as constant current or constant voltage, interleaving stimulation and up to four different stimulation groups.

The use of the remote control is easier for both physicians and patients. We did not find any technical data concerning the impact of the use of the remote control on battery longevity. However, we hypothesize that these supplemental electronic features of the Activa-PC ${ }^{\circledR}$ could drain the battery faster and impact battery longevity.

Moreover, the volume of the Activa-PC ${ }^{\circledR}$ is smaller than the Kinetra ${ }^{\circledR}$. Consequently, considering that the batteries are probably very similar (hybrid combined silver vanadium oxide), the Kinetra ${ }^{\circledR}$ battery should have around $20 \%$ more energy than the Activa-PC ${ }^{\circledR}$ battery $[23,24]$. 
Concerning the electronic circuits, it would be useful to know if the internal condensers of both models of neurostimulators are equal in number and capacity. If there were differences, this would imply that the two batteries had a different current leakage and consequently a different loss of energy through the condenser. This hypothesis should be explored in greater detail $[23,24]$.

Finally, noting that patients initially implanted with a Kinetra ${ }^{\circledR}$ need a specific adaptor to connect an Activa-PC ${ }^{\circledR}$ to the Kinetra ${ }^{\circledR}$ s extension cables, this adaptor could cause current leakage from the Activa-PC ${ }^{\circledR}$ battery and consequently a loss of energy. This point should be further explored to ensure that the rising diversity of DBS systems will be followed by the development of interconnectivity with efficient connection systems between DBS components from different devices [25].

\section{Successive neurostimulator replacements}

We found that the more replacement neurostimulators had been implanted in a patient, the faster a neurostimulator discharged, regardless of the neurostimulator type. This finding has already been debated [26-28] and is consistent with the recent study reported by Van Riesen et al. [9]. These authors showed that IPG longevity decreases as the number of replacements increases. This might be explained by the decreasing impedance over time [9,27], which is also consistent with the increase in the unmodified TEED over the years.

Secondarily, when a primo-implantation is performed, the electrical settings are initially lower than the chronic parameters. However, over the long term, the increase in the MDS-UPDRS motor score related to axial symptom worsening does not necessarily lead to a further increase in electrical parameters. Indeed, these symptoms are not improved by either levodopa or DBS. For this reason, in the long term, electrical parameters are unchanged after IPG replacement, whatever the neurostimulator type. Since 2012, Activa-PC ${ }^{\circledR}$ devices have been used for replacements. For patients who initially received a Kinetra ${ }^{\circledR}$, the newly implanted neurostimulators have been programmed with higher settings since the beginning, and this could at least partly impact their faster discharge compared to the Kinetra ${ }^{\circledR}$ used for primo-implantation. However, in our cohort, these changes are 
not significant for amplitude, frequency and pulse width [3]. The increase in the number of primoimplanted Activa-PC ${ }^{\circledR}$ over the coming years will make it possible to compare their lifetime in primoand secondary implantation.

\section{TEED and electrical parameters}

Depending on the adjusted hazard ratio, the modified TEED increased the risk of battery depletion. The calculation of the modified TEED is based on several electrical parameters, which are known to influence the devices' longevity $[7,27-31]$.

Helmers et al. found a higher modified TEED in the Kinetra ${ }^{\circledR}$ group compared to the Activa-PC ${ }^{\circledR}$ group and suggested that the shorter battery life of the Activa-PC ${ }^{\circledR}$ system was not due to a higher TEED. In our cohort, the electrical parameters used to calculate the modified TEED do not change with neurostimulator replacement, in the same patient. These apparent discrepancies could suggest that a higher TEED is probably not directly related to the neurostimulator type but rather to the long duration of DBS. These results are consistent with the fact that the impedances of the circuit decrease over time and induce an increase in the TEED [20], confirming other previous claims on the inverted correlation between the TEED and IPG longevity $[9,29]$.

\section{Male sex}

The results showed that male sex influenced battery longevity. Since the population is mainly composed of male patients, this result has a limited reliability because it could be biased by the unbalanced population.

\section{2) Limits of the study}

The first limitation of this study stems from its being conducted in a single center, although this allows analyzing a population treated with the same protocol in terms of battery management and surgery.

Second, we explored the relationships between DBS parameters and battery lifetime through a modified TEED. The missing data concerning impedances prevented us from calculating and comparing the true TEED of the Kinetra ${ }^{\circledR}$ and Activa-PC ${ }^{\circledR}$. This may bias the conclusions concerning 
the differential impact of stimulation parameters, impedances and neurostimulator type on longevity.

Third, fewer than five PD patients in our cohort actually use the new features of the Activa-PC ${ }^{\circledR}$. We could not differentiate two subgroups of patients, those using the new functionalities and those who did not. This prevented additional analysis, which could have confirmed that the use of additional functionalities of the Activa-PC ${ }^{\circledast}$, through repetitive connections to the neurostimulators and changes in electrical settings, has an impact on battery longevity.

Fourth, the longevity difference between the two types of neurostimulator may be overestimated due to different end-of-life indicators. The indicator of a low battery was an exact value for the Kinetra ${ }^{\circledast}$, whereas it is a range for the Activa-PC ${ }^{\circledR}$. The lack of experience with the Activa-PC ${ }^{\circledR} \mathrm{S}$ longevity when the parameters indicate that the battery is low implies that the neurostimulator is changed as soon as possible even if the indicator is still within the high range. If patients could be followed more closely, Activa-PC ${ }^{\circledR}$ longevity could perhaps be extended.

Finally, the economic evaluation presented is based on data provided by the National Costs Study of French Hospitals [21], and this may not properly take into account indirect and other costs such as the potential complications of the replacement, as well as days off work.

\section{3) Medical-economic perspective}

\section{Economic considerations}

The Activa-PC ${ }^{\circledast}$ has an overall cost higher than the Kinetra ${ }^{\circledR}$. A shorter battery life implies more replacements, with the associated surgical, medical and device costs as well as increased morbidity with all the potential surgical and postoperative complications of a replacement [11].

In the last few years, several patients with $\mathrm{Activa}^{-} \mathrm{PC}^{\circledR}$ have experienced an unexpected withdrawal syndrome due to battery depletion and abrupt cessation of stimulation [10]. DBS withdrawal syndrome was reported in PD patients successfully treated with long-duration STN DBS with low doses of chronic dopaminergic treatment. The rebound of PD symptoms and the lack of response to an increase in dopaminergic treatment after cessation of DBS may be life-threatening. This 
complication is reversible after neurostimulator reimplantation. Thus, anticipating neurostimulator replacement could have an indirect economic impact, for both the French healthcare system and industry.

One attempt to overcome the issue related to battery longevity is based on developing rechargeable DBS devices. According to the same National Costs Study of French Hospitals, the overall cost of a rechargeable Activa (Activa-RC ${ }^{\circledR}$ ) is 34,640 euros. Consequently, from an economic perspective, it can be more advantageous to implant rechargeable devices than nonrechargeable devices, at least after the first replacement. Previous economic studies showed that battery life has a strong impact on cost-effectiveness [16,32]. In particular, they demonstrated that DBS required fewer healthcare resources than long-term PD medical therapy [16,33-36]. Similar economic analyses should be performed concerning the replacement of nonrechargeable batteries compared to the use of rechargeable batteries. This economic claim must be modulated by patient considerations.

\section{Clinical and patient considerations}

It has been clearly demonstrated that the higher the number of surgeries, the higher the risk and number of infections, and that some patients experience recurrence of clinical symptoms during battery depletion [11,32,37-39]. Rechargeable devices seem advantageous in reducing recurrent operations and their complications.

Few studies report patient satisfaction concerning the use of RC devices $[37,39]$. The main limitations reported by physicians, as reported in these first studies, are related to the recharging process and thermal sensations. Patients suffering from other pathologies such as dementia may have limitations concerning the recharging process. Some authors suggest the use of rechargeable devices for young patients [37], whereas Jia's team [32] found no correlation between age and ease of use or comfort. They assessed the relevance of RC generators for elderly patients even if there is cognitive impairment because the risk of infections resulting from surgery is higher in these patients [32]. All studies emphasize the importance of patient education to learn how to use RC devices. 


\section{Conclusion}

Kinetra ${ }^{\circledR}$ neurostimulators have a longer lifetime than the Activa-PC ${ }^{\circledast}$ neurostimulator. This study contributes to our understanding of the technical properties of the rapidly evolving refinement of DBS devices.

Further studies on RC devices with large sample populations are needed to establish the place of RC IPGs as the treatment of choice for PD patients, in particular to establish their cost-effectiveness and to assess their long-term risks in patients who develop cognitive impairment over time, lose their caregiver and who are admitted to nursing homes.

\section{Figures and tables}

\section{Acknowledgements}

José Maria Clement, European Synchrotron Radiation Facility (ESRF), Grenoble, France, for his assistance in the analysis of the electronic devices.

Francesco Sette, European Synchrotron Radiation Facility (ESRF), Grenoble, France, for electrotechnical advice.

Frédéric Olive, for providing the National Costs Study of French Hospitals.

Linda Northrup, English Solutions, Voiron, France, for her assistance in American English copyediting. This study was developed within the framework of the Grenoble Alpes Data Institute, which is supported by the French National Research Agency under the "Investissements d'avenir" program (ANR-15-IDEX-02).

\section{Conflict of Interest:}

AC received travel grants from Boston Scientific, Medtronic, Elivie and a research fund from the France Parkinson association. EM received personal fees from Medtronic, BIAL, grants from Merz, and personal fees from Newronika. SC is a consultant for Medtronic, Boston Scientific and Zimmer Biomet. VF received personal fees for consultancy from AbbVie France. 


\section{References}

[1] Limousin P, Krack P, Pollak P, Benazzouz A, Ardouin C, Hoffmann D, et al. Electrical stimulation of the subthalamic nucleus in advanced Parkinson's disease. N Engl J Med 1998;339:1105-11. doi:10.1056/NEJM199810153391603.

[2] Vesper J, Klostermann F, Stockhammer F, Funk T, Brock M. Results of chronic subthalamic nucleus stimulation for Parkinson's disease: a 1-year follow-up study. Surg Neurol 2002;57:306-11; discussion 311-313.

[3] Krack P, Batir A, Van Blercom N, Chabardes S, Fraix V, Ardouin C, et al. Five-year follow-up of bilateral stimulation of the subthalamic nucleus in advanced Parkinson's disease. N Engl J Med 2003;349:1925-34. doi:10.1056/NEJMoa035275.

[4] Vora AK, Ward H, Foote KD, Goodman WK, Okun MS. Rebound symptoms following battery depletion in the NIH OCD DBS cohort: clinical and reimbursement issues. Brain Stimulat 2012;5:599-604. doi:10.1016/j.brs.2011.10.004.

[5] Alesch F. Sudden failure of dual channel pulse generators. Mov Disord Off J Mov Disord Soc 2005;20:64-6; discussion 66. doi:10.1002/mds.20354.

[6] Tagliati M, Martin C, Alterman R. Lack of motor symptoms progression in Parkinson's disease patients with long-term bilateral subthalamic deep brain stimulation. Int J Neurosci 2010;120:717-23. doi:10.3109/00207454.2010.518777.

[7] Anheim M, Batir A, Fraix V, Silem M, Chabardès S, Seigneuret E, et al. Improvement in Parkinson disease by subthalamic nucleus stimulation based on electrode placement: effects of reimplantation. Arch Neurol 2008;65:612-6. doi:10.1001/archneur.65.5.612.

[8] Fakhar K, Hastings E, Butson CR, Foote KD, Zeilman P, Okun MS. Management of deep brain stimulator battery failure: battery estimators, charge density, and importance of clinical symptoms. PloS One 2013;8:e58665. doi:10.1371/journal.pone.0058665.

[9] Van CR, Tsironis G, Gruber D, Klostermann F, Krause P, Schneider GH, et al. Disease-specific longevity of impulse generators in deep brain stimulation and review of the literature. J Neural Transm Vienna Austria 1996 2016;123:621-30. doi:10.1007/s00702-016-1562-1.

[10] Castrioto A, Lhommée E, Moro E, Krack P. Mood and behavioural effects of subthalamic stimulation in Parkinson's disease. Lancet Neurol 2014;13:287-305. doi:10.1016/S1474-4422(13)70294-1.

[11] Pepper J, Zrinzo L, Mirza B, Foltynie T, Limousin P, Hariz M. The risk of hardware infection in deep brain stimulation surgery is greater at impulse generator replacement than at the primary procedure. Stereotact Funct Neurosurg 2013;91:56-65. doi:10.1159/000343202.

[12] Thrane JF, Sunde NA, Bergholt B, Rosendal F. Increasing infection rate in multiple implanted pulse generator changes in movement disorder patients treated with deep brain stimulation. Stereotact Funct Neurosurg 2014;92:360-4. doi:10.1159/000365576.

[13] Drapier D, Péron J, Leray E, Sauleau P, Biseul I, Drapier S, et al. Emotion recognition impairment and apathy after subthalamic nucleus stimulation in Parkinson's disease have separate neural substrates. Neuropsychologia 2008;46:2796-801. doi:10.1016/j.neuropsychologia.2008.05.006.

[14] Martinez-Fernandez R, Pelissier P, Quesada J-L, Klinger H, Lhommée E, Schmitt E, et al. Postoperative apathy can neutralise benefits in quality of life after subthalamic stimulation for Parkinson's disease. J Neurol Neurosurg Psychiatry 2016;87:311-8. doi:10.1136/jnnp-2014-310189.

[15] Allert N, Kirsch H, Weirich W, Karbe H. Stability of symptom control after replacement of impulse 
generators for deep brain stimulation. J Neurosurg 2009;110:1274-7. doi:10.3171/2009.1.JNS081352.

[16] Dams J, Siebert U, Bornschein B, Volkmann J, Deuschl G, Oertel WH, et al. Cost-effectiveness of deep brain stimulation in patients with Parkinson's disease. Mov Disord Off J Mov Disord Soc 2013;28:763-71. doi:10.1002/mds.25407.

[17] Helmers A-K, Lübbing I, Deuschl G, Witt K, Synowitz M, Mehdorn HM, et al. Comparison of the Battery Life of Nonrechargeable Generators for Deep Brain Stimulation. Neuromodulation J Int Neuromodulation Soc 2017. doi:10.1111/ner.12720.

[18] Medtronic Activa ${ }^{\circledR}$ PC 37601 Multi-program neurostimulator n.d.

[19] Medtronic Kinetra ${ }^{\circledR} 7428$ Dual Program Neurostimulator for Deep Brain Stimulation n.d.

[20] Koss AM, Alterman RL, Tagliati M, Shils JL. Calculating total electrical energy delivered by deep brain stimulation systems. Ann Neurol 2005;58:168; author reply 168-169. doi:10.1002/ana.20525.

[21] ATIH. Etude Nationale des coûts ENC-MCO 2016 n.d.

[22] Rawal PV, Almeida L, Smelser LB, Huang H, Guthrie BL, Walker HC. Shorter pulse generator longevity and more frequent stimulator adjustments with pallidal DBS for dystonia versus other movement disorders. Brain Stimulat 2014;7:345-9. doi:10.1016/j.brs.2014.01.008.

[23] Takeuchi ES, Quattrini PJ, Greatbatch W. Lithium/silver vanadium oxide batteries for implantable defibrillators. Pacing Clin Electrophysiol PACE 1988;11:2035-9.

[24] Bock DC, Marschilok AC, Takeuchi KJ, Takeuchi ES. Batteries used to Power Implantable Biomedical Devices. Electrochimica Acta 2012;84. doi:10.1016/j.electacta.2012.03.057.

[25] Amon A, Alesch F. Systems for deep brain stimulation: review of technical features. J Neural Transm 2017;124:1083-91. doi:10.1007/s00702-017-1751-6.

[26] Lumsden DE, Kaminska M, Tustin K, Gimeno H, Baker L, Ashkan K, et al. Battery life following pallidal deep brain stimulation (DBS) in children and young people with severe primary and secondary dystonia. Childs Nerv Syst 2012;28:1091-7. doi:10.1007/s00381-012-1728-6.

[27] Halpern CH, McGill KR, Baltuch GH, Jaggi JL. Longevity Analysis of Currently Available Deep Brain Stimulation Devices. Stereotact Funct Neurosurg 2011;89:1-5. doi:10.1159/000321710.

[28] Blahak C, Capelle H-H, Baezner H, Kinfe TM, Hennerici MG, Krauss JK. Battery lifetime in pallidal deep brain stimulation for dystonia. Eur J Neurol 2011;18:872-5. doi:10.1111/j.1468-1331.2010.03290.x.

[29] Bin-Mahfoodh M, Hamani C, Sime E, Lozano AM. Longevity of batteries in internal pulse generators used for deep brain stimulation. Stereotact Funct Neurosurg 2003;80:56-60. doi:10.1159/000075161.

[30] Ondo WG, Meilak C, Vuong KD. Predictors of battery life for the Activa Soletra 7426 Neurostimulator. Parkinsonism Relat Disord 2007;13:240-2. doi:10.1016/j.parkreldis.2006.11.002.

[31] Isaias IU, Alterman RL, Tagliati M. Deep brain stimulation for primary generalized dystonia: long-term outcomes. Arch Neurol 2009;66:465-70. doi:10.1001/archneurol.2009.20.

[32] Jia F, Hao H, Meng F, Guo Y, Zhang S, Zhang J, et al. Patient perspectives on the efficacy of a new kind of rechargeable deep brain stimulators(1). Int J Neurosci 2016;126:996-1001.

doi:10.3109/00207454.2015.1092145.

[33] Fraix V, Houeto J-L, Lagrange C, Le Pen C, Krystkowiak P, Guehl D, et al. Clinical and economic results of bilateral subthalamic nucleus stimulation in Parkinson's disease. J Neurol Neurosurg Psychiatry 2006;77:443-9. doi:10.1136/jnnp.2005.077677.

[34] Valldeoriola F, Puig-Junoy J, Puig-Peiró R, Workgroup of the SCOPE study. Cost analysis of the 
treatments for patients with advanced Parkinson's disease: SCOPE study. J Med Econ 2013;16:191-201. doi:10.3111/13696998.2012.737392.

[35] Eggington S, Valldeoriola F, Chaudhuri KR, Ashkan K, Annoni E, Deuschl G. The cost-effectiveness of deep brain stimulation in combination with best medical therapy, versus best medical therapy alone, in advanced Parkinson's disease. J Neurol 2014;261:106-16. doi:10.1007/s00415-013-7148-z.

[36] Becerra JE, Zorro O, Ruiz-Gaviria R, Castañeda-Cardona C, Otálora-Esteban M, Henao S, et al. Economic Analysis of Deep Brain Stimulation in Parkinson Disease: Systematic Review of the Literature. World Neurosurg 2016;93:44-9. doi:10.1016/j.wneu.2016.05.028.

[37] Timmermann L, Volkmann J. [Deep brain stimulation for treatment of dystonia and tremor]. Nervenarzt 2010;81:680-7. doi:10.1007/s00115-010-2939-2.

[38] Gillies MJ, Joint C, Forrow B, Fletcher C, Green AL, Aziz TZ. Rechargeable vs. nonrechargeable internal pulse generators in the management of dystonia. Neuromodulation J Int Neuromodulation Soc 2013;16:226-9; discussion 229. doi:10.1111/ner.12026.

[39] Waln O, Jimenez-Shahed J. Rechargeable deep brain stimulation implantable pulse generators in movement disorders: patient satisfaction and conversion parameters. Neuromodulation J Int Neuromodulation Soc 2014;17:425-30; discussion 430. doi:10.1111/ner.12115. 


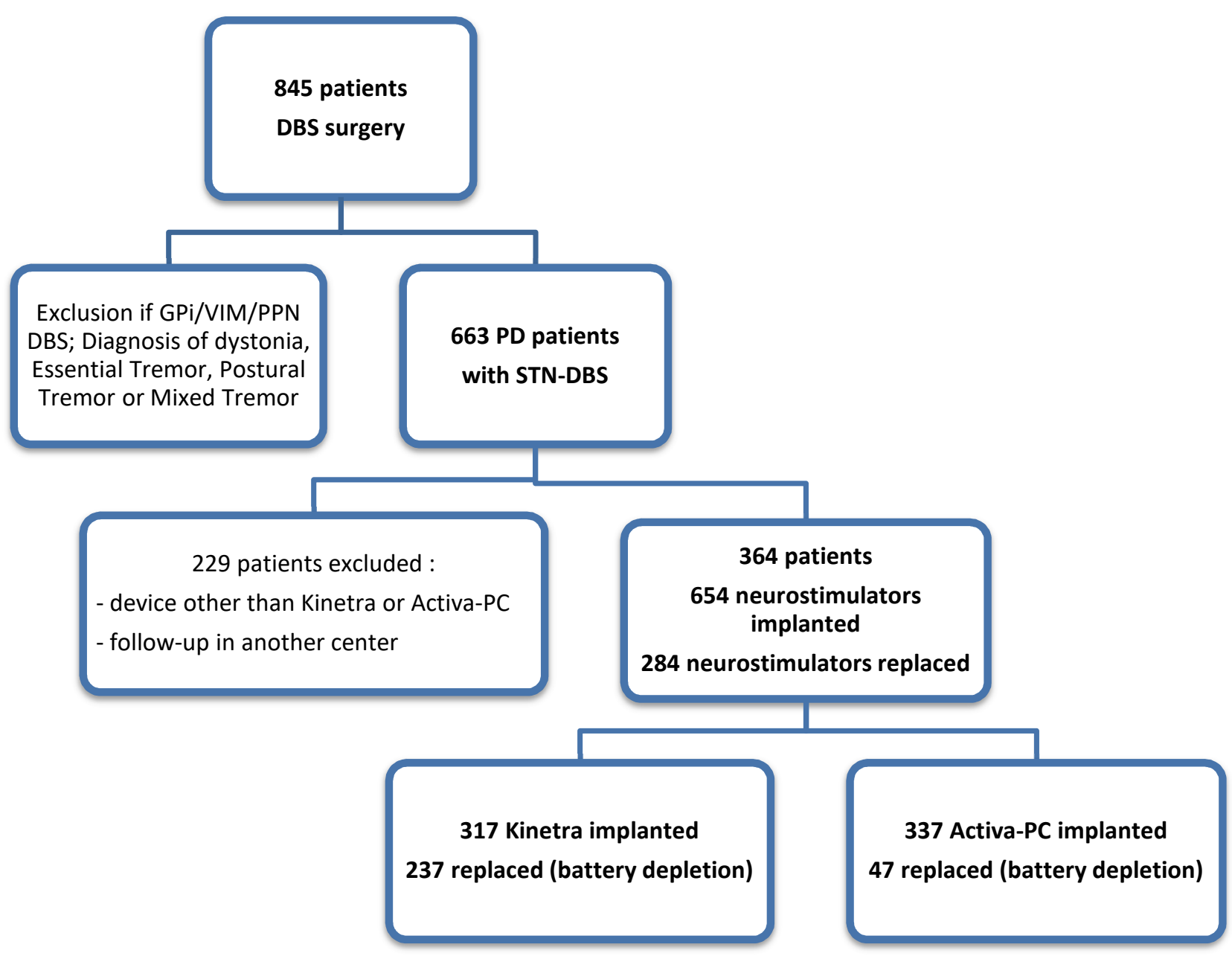


Figure 2: Kaplan-Meier survival curves of Kinetra and Activa-PC batteries.

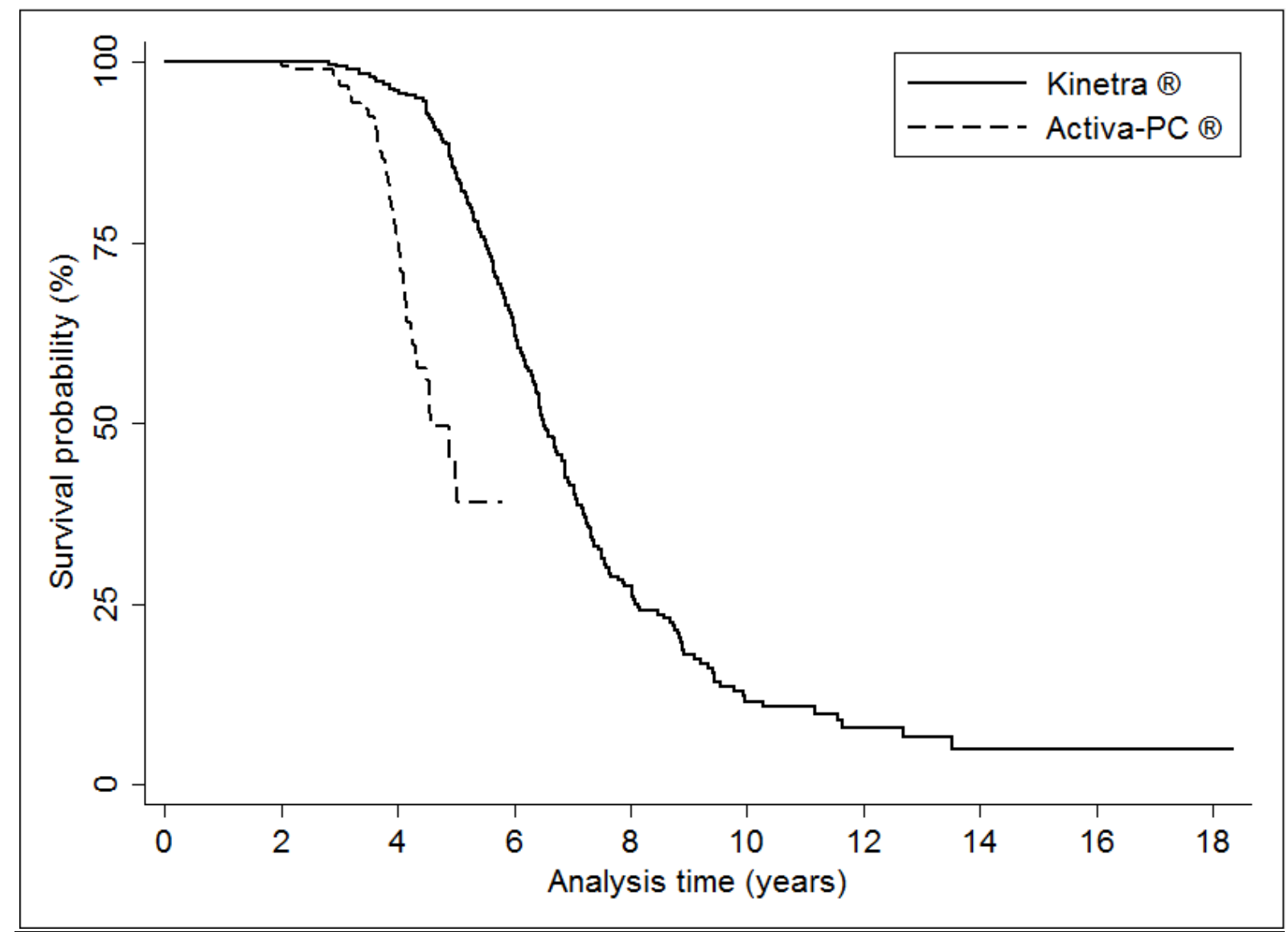


Table 1: Physical characteristics of the Kinetra ${ }^{\circledR}$ and Activa-PC ${ }^{\circledR}$ devices

\section{Kinetra ${ }^{\circledR}$ Model 7428}

Programmable parameters

\section{Battery characteristics}

Height

Length

Thickness

Volume

Power source
One program

Amplitude (V)

Pulse width ( $\mu \mathrm{s})$

Rate $(\mathrm{Hz})$

Electrode polarity

Mode continuous or discontinuous

$10 \mathrm{~mm}$

$40 \mathrm{~mm}$

$28 \mathrm{~mm}$

$16,245.7 \mathrm{~mm} 3$

Unknown

Hybrid combined silver vanadium oxide
Activa-PC ${ }^{\circledR}$ Model 37601

Up to 4 programs

Amplitude (V)

Pulse width ( $\mu s)$

Rate $(\mathrm{Hz})$

Electrode polarity

Mode continuous or discontinuous Interleaving stimulation
$11 \mathrm{~mm}$
$45 \mathrm{~mm}$
$28 \mathrm{~mm}$
$13,430.3 \mathrm{~mm} 3$
6.3 Amp hours, $3.2 \mathrm{~V}$
Hybrid combined silver vanadium oxide 
Table 2: Stimulation parameters' characteristics

\begin{tabular}{lll} 
Parameters & Mean & Standard deviation (SD) \\
\hline \hline Amplitude (V) & $2.86 \mathrm{~V}$ & $0.57 \mathrm{~V}$ \\
Frequency (Hz) & $133 \mathrm{~Hz}$ & $21 \mathrm{~Hz}$ \\
Pulse width ( $\mu \mathrm{s})$ & $61.86 \mu \mathrm{s}$ & $6.24 \mu \mathrm{s}$ \\
Modified TEED & 71,762 & 28,937
\end{tabular}


Table 3: Mean duration of depleted neurostimulators according to the number of neurostimulators replaced and the type

\begin{tabular}{|c|c|c|c|}
\hline $\begin{array}{l}\text { Number of neurostimulators } \\
\text { successively replaced }\end{array}$ & $\begin{array}{l}\text { Mean duration Kinetra } \\
\text { (days) }\end{array}$ & $\begin{array}{l}\text { Mean duration Activa } \\
\text { (days) }\end{array}$ & $\begin{array}{c}\text { P-value } \\
\text { Kinetra vs Activa }\end{array}$ \\
\hline 1 ( $n=180)$, days & 2460 & 1544 & $<0.001$ \\
\hline $2(n=75)$, days & 2072 & 1323 & $<0.001$ \\
\hline $3(n=24)$, days & 1721 & 1400 & 0.01 \\
\hline$>3(n=5)$, days & 1403 & 1187 & 0.40 \\
\hline$p$ for trend & $<0.001$ & $<0.001$ & \\
\hline
\end{tabular}


Table 4: Risk factors' crude and adjusted hazard ratio of the Cox model

\begin{tabular}{|c|c|c|c|c|}
\hline Ranking & $\begin{array}{l}\text { Crude } \\
\text { Hazard } \\
\text { Ratio }\end{array}$ & $\begin{array}{l}95 \% \\
\text { Interval }\end{array}$ & $\begin{array}{l}\text { Adjusted } \\
\text { Hazard Ratio }\end{array}$ & $\begin{array}{l}95 \% \\
\text { Confidence } \\
\text { Interval }\end{array}$ \\
\hline \multicolumn{5}{|l|}{ Type of neurostimulator } \\
\hline KINETRA & 1.00 & - & 1.00 & - \\
\hline ACTIVA & 4.77 & {$[3.23-7.03]$} & 4.04 & {$[2.65-6.17]$} \\
\hline \multicolumn{5}{|l|}{ Sex } \\
\hline Female & 1.00 & - & 1.00 & - \\
\hline Male & 1.30 & {$[1.01-1.67]$} & 1.47 & {$[1.12-1.94]$} \\
\hline \multicolumn{5}{|l|}{ Primo-implantation age } \\
\hline$\leq 51,6$ & 1.00 & - & 1.00 & - \\
\hline ]51,6-62] & 0.91 & {$[0.69-1.19]$} & 1.10 & {$[0.82-1.47]$} \\
\hline$>62$ & 0.63 & {$[0.44-0.91]$} & 1.09 & {$[0.73-1.62]$} \\
\hline IPG replacement number & 2.12 & {$[1.78-2.52]$} & 1.71 & {$[1.42-2.07]$} \\
\hline \multicolumn{5}{|l|}{ Modified TEED (mean) } \\
\hline$<50000$ & 1.00 & - & 1.00 & - \\
\hline [50000 - 70500] & 1.45 & {$[0.97-2.17]$} & 1.30 & {$[0.87-1.94]$} \\
\hline [70501 - 87711] & 1.83 & {$[1.25-2.69]$} & 1.60 & {$[1.08-2.37]$} \\
\hline$>87711$ & 2.45 & {$[1.68-3.57]$} & 2.02 & {$[1.37-3.00]$} \\
\hline \multicolumn{5}{|c|}{ Number of activated contacts } \\
\hline$\leq 2$ & 1.00 & - & 1.00 & - \\
\hline$>2$ & 0.97 & {$[0.71-1.32]$} & 1.04 & {$[0.75-1.45]$} \\
\hline
\end{tabular}

